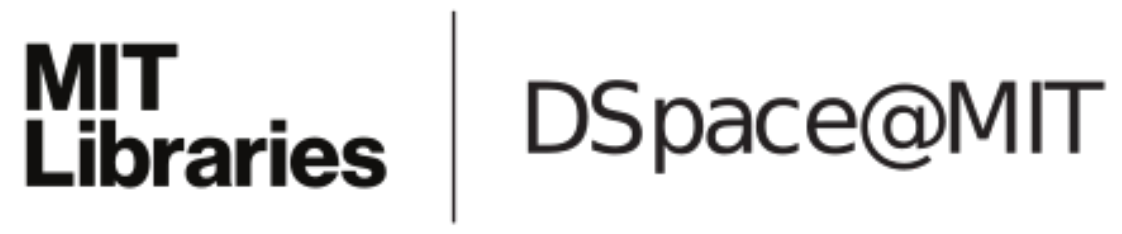

\author{
MIT Open Access Articles
}

Improving assistive technology economics for people with disabilities: Harnessing the voluntary and education sectors

The MIT Faculty has made this article openly available. Please share how this access benefits you. Your story matters.

Citation: Li, W., and C. Sellers. "Improving assistive technology economics for people with disabilities: Harnessing the voluntary and education sectors." Science and Technology for Humanity (TIC-STH), 2009 IEEE Toronto International Conference. 2009. 789-794. (C Copyright 2010 IEEE

As Published: http://dx.doi.org/10.1109/TIC-STH.2009.5444391

Publisher: Institute of Electrical and Electronics Engineers

Persistent URL: http://hdl.handle.net/1721.1/59829

Version: Final published version: final published article, as it appeared in a journal, conference proceedings, or other formally published context

Terms of Use: Article is made available in accordance with the publisher's policy and may be subject to US copyright law. Please refer to the publisher's site for terms of use. 


\section{Improving Assistive Technology Economics for People with Disabilities: Harnessing the Voluntary and Education Sectors}

\author{
William Li, Student Member, IEEE \\ Technology and Policy Program, Engineering Systems \\ Division, Massachusetts Institute of Technology \\ 77 Massachusetts Avenue, Cambridge, USA \\ williamli@ieee.org
}

\author{
Clara Sellers, Student Member, IEEE \\ History and Philosophy of Science and Technology \\ University of King's College \\ 6350 Coburg Road, Halifax, Canada \\ clara.sellers@gmail.com
}

\begin{abstract}
Assistive technology (AT) describes any device or other solution that is used by people with disabilities to assist in performing tasks or activities. While potentially useful, the availability of appropriate AT for people with disabilities can be problematic due to high costs, limited funding sources, and a lack of expertise on what solutions might exist for their needs. This paper explores the potential power of technical volunteers in collaboration with the education sector to address the problem of high AT costs for certain classes of assistive devices by providing a volunteer force of skilled engineers, designers, and other technicians who donate their time and goodwill to building appropriate, low-cost assistive devices. It presents a number of case studies on AT-related volunteer organizations and postsecondary educational initiatives, and discusses the possible growth of such initiatives. We propose a path forward to build a social movement of volunteers, modeled after the success of organizations such as Engineers Without Borders (EWB) Canada, Teach for America, and CanAssist at the University of Victoria to improve the quality of life of people with disabilities.
\end{abstract}

Keywords-assistive technology; economics; engineering; education; service learning; volunteerism

\section{INTRODUCTION}

In Canada, 4.4 million people, or $14.3 \%$ of the population, have a disability [1]. As the population ages, as better treatments for previously lethal diseases such as spinal cord injury emerge, and as neonatal survival rates improve, the prevalence of disability continues to rise [2]. Disabilities can be mental or physical, and cause challenges to effective personal care, mobility, learning, communication, or other daily activities [3].

Assistive technology (AT) refers to any item, piece of equipment, or system, whether acquired commercially, modified, or customized, that is commonly used to increase, maintain, or improve functional capabilities of individuals with disabilities [4]. Given that the spectrum of disabilities varies widely in type and severity, AT encompasses an enormous range of devices, including mobility aids (wheelchairs, canes, and walkers), augmentative communication devices (voice synthesizers and communication boards), prosthetic and orthotic devices, and a myriad of adaptive computer equipment. AT can be "low- tech" (a cup-holder for a wheelchair tray) or "high-tech" (brain-computer interfaces for communication and environmental control). AT can help people with disabilities improve their quality of life, contribute economically and socially, and increase their independence [5].

While potentially useful, the availability of appropriate AT for people with disabilities can be problematic. A 2009 content analysis of common concerns of people living with disabilities found that assistive technology was the second most common concern [6]. Most notably, due to the specialized needs of each person with a disability, the market for one particular assistive device may be exceedingly small, driving up the cost of specialized assistive devices. The high cost of AT compounds the problem of finding an appropriate AT device: people may not be able to afford to try different devices and loan programs can be cost-prohibitive [7]. Second, due to small markets, and the limited capacities of the AT commercial sector, appropriate assistive devices may simply not exist for many specialized needs, or potential users may not be aware of them.

This paper explores the potential power of skilled technical volunteers and of the education sector to address the problem of prohibitive costs for certain classes of assistive devices. It presents Canadian case studies on AT-related volunteer organizations and post-secondary educational initiatives, discusses models for growth of such initiatives, and proposes a path forward, drawing on the existing strengths of these organizations, to make useful and affordable AT a reality for people living with disabilities.

\section{CurRent State of Assistive Technology ECONOMICS}

Several possible solutions exist to make AT more affordable and appropriate for its users' needs. The successes and limitations of these approaches reveal why the voluntary and education sectors may fill an important gap.

\section{A. Overview of Current Approaches}

\section{1) Commercial Assistive Devices}

Many assistive devices are produced by for-profit enterprises that meet a market need. Such devices generally 
serve more prevalent disabilities since larger markets result in greater economies of scale. Additionally, these devices might be medically necessary, meaning that they can be funded by health care systems or other sources. The commercial AT sector serves a substantial fraction of people with disabilities. That said, commercial AT is expensive since the overall size of markets is still small. As well, businesses generally neglect very specialized AT needs that are less common. Because this market approach limits the capacity for customization of AT, many AT users find that the available technologies do not meet their needs and elect to not use AT. A systematic review of peoples' perceptions of recommended assistive technologies found high rates of non-use among people with disabilities across all studies, ranging from $35 \%$ to $87 \%$ [8].

\section{2) Grants and Government Funding}

Given the capacity of AT to improve quality of life, independence, and economic productivity, providing individuals with the financial means to purchase assistive devices could be economically sensible. In the United States, approximately half of all assistive devices are partially paid for by third-party sources such as charities or government grants [9]. While grants and government funding do help make assistive devices affordable for some people, this funding is finite due to the many demands and other priorities in an already strained system. The high cost of AT and the lack of solutions for certain segments of the population also limit the reach of grants for people with disabilities.

\section{3) Universal Design Principles}

From a high-level societal systems standpoint, the need for assistive devices could be reduced by making communities and environments more accessible. Universal design is a concept with a growing level of acceptance among designers and refers to designing standard environments that people with the widest possible range of abilities can use and access [10]. In an ideal universally accessible society, there should not be a difference in the ability of people with and without disabilities to function effectively, thereby eliminating the need for AT.

Although universal design should be embraced and is an important idea, the immense challenges faced by people with disabilities today suggest that AT remains necessary to assist people with disabilities perform important activities. Furthermore, some individuals may not be able to perform certain tasks without the use of assistive devices because truly universal environments may not be achievable. For example, it may be more realistic for a person who is non-verbal to use an augmentative communication device as opposed to a situation where the entire community communicates in a manner that does not require verbal skills.

\section{B. Remaining Gaps}

The activities of businesses, government grants, and universal designers help to meet the AT needs of people with disabilities, but they are insufficient. Specifically, they fail to address the following problems:

- Solutions for specific assistive needs simply may not exist due to prohibitively small market sizes.
- Assistive devices that serve small markets may not be affordable, even with the assistance of third-party grants.

\section{A ROLE FOR THE VOLUNTARY AND EDUCATION SECTORS}

In light of these key gaps in AT customizability and affordability, there is a need for innovative solutions to increase the availability and decrease the cost of appropriate assistive devices for people with disabilities.

Given that disabilities differ so greatly from person to person, no broad market-based solution exists to meet all of their needs. A more effective approach is to address AT needs on a case-by-case basis and to develop original and customized technologies in consultation with the user. A possible systemwide solution could be to introduce a base of technically skilled volunteers who fill the gap by donating their time and expertise to developing custom assistive devices for people with disabilities. In contrast to a for-profit model in developing customized devices, an approach that uses skilled volunteers overcomes the barrier of the high costs associated with serving a very small market. By reducing the labour costs of engineering new assistive devices, volunteers make AT affordable for all people living with disabilities and not just for a niche high-income market.

\section{The Volunteer Sector in Canada}

This mobilization of volunteers will be easiest and most successful in countries where a strong volunteer sector already exists. There is already a strong volunteer base in Canada. In 2004, the Canada Survey on Giving, Volunteering and Participating found that 11.8 million Canadians-nearly fifty percent of all Canadians over fifteen-volunteered that year [11] Together, their contributions totaled to two billion volunteer hours, which is the equivalent of one million full-time jobs. Significantly, the top three reasons for volunteering were "to make a contribution to the community, to use one's skills and experiences, and being affected by the cause supported by the organization" [11]. All three reasons, and particularly the emphasis on using one's skills, are pertinent to the involvement of the voluntary sector in developing AT. From these findings, one can conclude that a voluntary assistive technology sector is in line with current volunteerism trends in Canada, and would likely be endorsed by the public.

Overall, the voluntary and education sectors fulfill an important role: they can provide technical skills to design and build assistive devices for which the markets are too small to be pursued by commercial enterprises. This is possible by appealing to the goodwill of individuals and the social bottom line of educational institutions. Figure 1 describes this framework. Some successful community- and institutionbased organizations that serve AT users are discussed below.

\section{A. Tetra Society of North America}

Founded in 1987, the Tetra Society consists of volunteer engineers, technicians, students, and health professions to build assistive devices requested by people with disabilities. A 


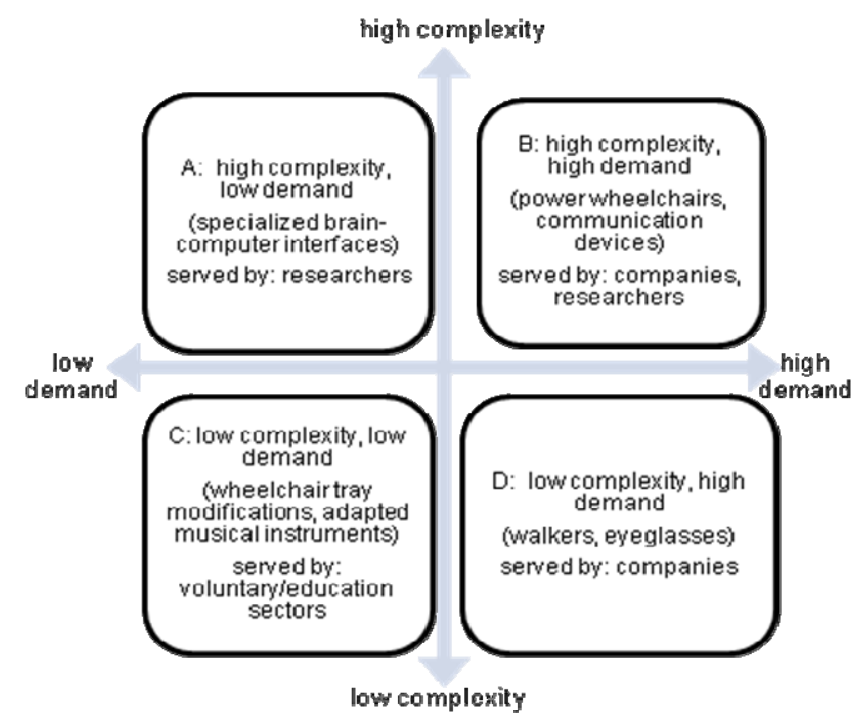

Figure 1. Complexity/demand framework for assistive technology.

person with a disability makes a request for assistance and Tetra matches a volunteer to assess the need and build the device. The service is free and clients only pay for materials and volunteer expenses. Today, Tetra consists of volunteers across Canada and the United States, with chapters located in 45 major cities and urban areas. Today, the group has approximately 180 volunteers, 45 chapters of different sizes, takes on 250 projects annually, and has completed 3000 projects since 1987. Volunteers undertake many different types of projects, including making adapted toys for children with disabilities, constructing desks that are accessible for a wheelchair user, and designing customized computer access interfaces for individuals [12].

\section{B. Academic Research Groups}

For assistive technology that has substantial technical research challenges, academic research funding sources have generated research-and-development capital that would otherwise have been unavailable.

For example, academic researchers at Bloorview Kids Rehab in Toronto, Canada, along with researchers in other affiliated hospitals, have worked on a device that assists caregivers of people with dysphagia, a condition that describes difficulties in swallowing food. With funding from the Natural Science and Engineering Research Council (NSERC), the Canadian Institutes of Health Research, and other sources, the group has developed a non-invasive device that detects whether the user is at a risk of intaking food into the lungs [13] that is now in its final stages of pre-commercialization with an industry partner.

Similarly, researchers at the Toronto Rehabilitation Institute have developed an assistive device called $\mathrm{COACH}$ (Cognitive Orthosis for Assisting with aCtivites in the Home) that assists individuals with dementia with hand-washing activities by using artificial intelligence algorithms and computer vision. The system provides cues or reminders if a person forgets a step in the hand-washing process. Studies with $\mathrm{COACH}$ have shown that, with patients with moderate dementia, the system reduces the amount of caregiver assistance necessary during hand-washing, which could lead to more cost-effective care in places like seniors' homes and independent living facilities [14].

Finally, a third example of how assistive technology has advanced through academic research is in the broad area of prosthetic devices. Several institutions, including the Institute of Biomedical Engineering at the University of New Brunswick, have built strong and well-funded research programs tackling the technical and usability challenges with prosthetic devices, especially with a focus on signal processing issues. Support for prosthetics research is most evident in the United States, with multiple initiatives funded by different government agencies. For example, the Rehabilitation Engineering Research Center (RERC) on Prosthetics and Orthotics in the Feinberg School of Medicine and McCormick School of Engineering at Northwestern University (Chicago, IL) receives sustainable funding in fiveyear blocks from the National Institute on Disability and Rehabilitation Research (NIDRR). Meanwhile, the Revolutionizing Prosthetics Program, funded by the Defense Advanced Research Projects Agency (DARPA), has enabled major innovations in prosthetics research among groups at Johns Hopkins University Applied Physics Lab and its partners [15].

Although academic research has been shown to successfully advance the technical capabilities of AT, it is worth noting that its usefulness in improving AT economics may be limited by an important caveat: the ownership of intellectual property and the eventual affordability of developed devices. Ideally, research supported by public funds will enter the public domain and result in affordable AT, but due to commercialization pressures, licensing agreements, and funding by industry sources, this may not necessarily be the case. In general, though, it is possible to conclude that academic research funding provides additional resources that make new assistive technology possible and reduce the research-and-development costs that are eventually passed on to users. By presenting the needs of people with disabilities as important scientific research programs, these groups have successfully leveraged funding and resources (professional or training researchers) that would not otherwise be available to assistive technology users.

\section{Engineering Education Curricula}

To provide a continuous source of new volunteers to work on projects and to develop sustainable interest among the next generation of skilled individuals, one possibility is to incorporate assistive technology projects into university or college curricula in technical subjects, including engineering, industrial design, and the technical trades. In particular, the technical, design, problem-solving, and service-learning nature of building low-cost, specialized assistive devices could make it a natural fit for Canadian engineering curricula, a source of approximately 60,000 undergraduate students. Such projects 
could be compelling because they are manageable in scope for training engineers, offer opportunities to work with real clients, and demonstrate the positive impacts that engineering can have on people's lives. There is also strong theoretical support for incorporating service learning-based components into coursework: A 1998 Astin and Sax study found that "participation in voluntary work during the undergraduate years enhances students' academic development, life skills development, and sense of civic responsibility. In addition, volunteering can enhance students' job experience, help them choose the right vocation, and improve students' resumes and opportunities as they leave the university and seek jobs" [16].

Within the engineering curriculum, three types of courses might match community AT needs particularly well:

1) First-Year Courses: At many universities, first-year engineering students take an engineering design course that introduces them to the profession of engineering, the problemsolving process, and communication skills. For instance, at the University of Manitoba, first-year students in the winter 2007 iteration of Engineering 113: Engineering Communication and Design took on projects focused on devices needed by the aforementioned Tetra Society of North America [17]. Given the limited technical expertise of freshman engineering students, simpler projects or the mentorship of an experienced skilled volunteer engineer or technician may help improve the success of these projects. Similar models have been deployed or are planned at other North American institutions [18].

2) Upper-Year Design Courses: Engineering students with some expertise in a particular field could be a good fit for upper-year engineering courses with an AT component. Indeed, some design courses that have a focus on assistive technology already exist. For example, a third-year course called "Introduction to Design" in the Department of Systems Design Engineering at the University of Waterloo has focused on different medical conditions, from Alzheimer's Disease to cerebral palsy, and challenged students to develop appropriate devices or solutions improve the quality of life of people who may have these conditions [19]. While these projects have generally been less focused on one particular client and more on the needs of a particular population with a certain disability, students visit rehabilitation hopsitals, seniors' homes, or meet with individuals with disabilities directly in order to understand their realities and challenges. The designs and prototypes that emerge from courses such as this one have the potential to be manufactured, tested, and even commercialized for the target population.

\section{SCALING UP THE IMPACT OF THE VOLUNTARY AND EDUCATION SECTORS}

The initiatives discussed in the preceding section have an important role to play in improving AT customizability and affordability. The following initiatives have been successful in scaling up the impact of the voluntary and education sectors, and are useful models for AT organizations seeking to increase the impact of the quality work they are already doing.

\section{A. Engineers Without Borders (EWB) Canada}

Founded in 2000, Engineers Without Borders (EWB) Canada had humble beginnings as a two-person volunteer organization. Within a decade, it has grown enormously: today, it has 28 university chapters and 9 professional chapters across the country, 40000 members, a full-time staff of 15 people at its head office in Toronto, and its active leaders alone count over one million volunteer hours per year, the equivalent of 500 full-time employees. EWB's success has been founded on sound organizational strategy and management; in particular, it has effectively leveraged of the extracurricular involvement of thousands of university engineering and non-engineering students [20] and supporters. These efforts have led to high levels of respect and credibility in the Canadian international development sector and substantial achievements in EWB's two areas of focus: sending highly trained, effective Canadian volunteers overseas to four countries in West and Southern Africa, and advocating for pro-development policies in Canada.

The success of EWB, especially in engaging student and professional engineers, underscores two important points. First, the popularity of EWB as a movement highlights the passion of young Canadian engineers not just for doing well, but for doing good - a deep well of skilled, passionate volunteers who are interested in social justice and taking action exists. Second, EWB demonstrates that, even with a relatively small paid staff devoted to volunteer management, a diffuse network of volunteers in a country as geographically vast as Canada can work together for a common purpose. Both of these attributes would be important characteristics of scaling up the number of technically skilled volunteers who dedicate time to build assistive devices to meet specific needs of people with disabilities.

\section{B. Teach for America (USA)}

Some important parallels exist between the need for skilled volunteers to build assistive technology and Teach for America (TFA), a U.S.-based charity that identifies high-performing college graduates in all study areas with leadership potential to teach in low-income communities across the United States. TFA was founded in 1989, and now there are over 7,000 TFA teachers in over 1,600 schools, with nearly 17,000 alumni who have first-hand experience with the inequities of the U.S. public education system. Its teaching members serve a minimum of two years and are considered during that time as part of the TFA Corps. It now receives more applicants who meet its rigorous academic and leadership requirements, and it has been noted as a significant source of teaching talent for low-income communities. TFA teachers have been shown in studies to have a positive impact on students in the classroom, particularly in the areas of math and science [21].

The growth and popularity of TFA speaks to the interest of individuals to apply their skills toward making a positive impact, and that this energy and passion can be scaled up if managed properly. Many Corps members sacrifice lucrative academic and employment opportunities elsewhere to serve low-income communities through their talent as educators. An additional feature of the TFA philosophy is that it believes strongly in creating a network of Corps alumni who have an 
understanding of the inequities in the U.S. public education system.

Along these lines, technically skilled volunteers could contribute their passion and energy in engineering and design to assisting people with disabilities. In doing so, they will gain an opportunity work with people with special needs and understand their realities, an important step toward further societal change.

\section{CanAssist}

Founded in 1999 at the University of Victoria in British Columbia, CanAssist is a university-based initiative dedicated to developing innovative technologies for people with disabilities to help them with everyday activities. The growth of CanAssist has been remarkable within a single decade. The group works on 50 projects annually, has grown to 26 fulltime staff, and received a \$3 million grant from the British Columbia Ministry of Employment and Income Assistance and the Ministry of Advanced Education to support its general operations. Since its inception, CanAssist has engaged more than 2200 students, 200 faculty members and community volunteers, and is now the largest co-op employer of University of Victoria undergraduate engineering students [22].

Along with completing unique, innovative, and affordable assistive technology projects, CanAssist conducts academic research on more advanced assistive technologies [23], [24]. It also plans a "Dynamic Factory" in which people with disabilities can manufacture and assemble assistive devices. CanAssist embodies a university-community-government partnership that benefits from academic research support, education funding, and the power of volunteerism to improve AT economics for people with disabilities. In this way, it represents a fusion of community groups like the Tetra Society and academic research groups elsewhere. Based on the CanAssist model, collaboration between existing research groups and the voluntary sector could yield positive results.

\section{A POSSIBLE PATH FORWARD}

Currently, there are exciting and innovative volunteer initiatives in the area of AT development. However, they have potential to have an even greater impact and drive a change towards individualized, appropriate and affordable AT. Scaling up and improving connectivity are two solutions that organizations could champion to increase their reach. Engineers Without Borders, Teach for America, and CanAssist have all grown successfully into high impact organizations, and are workable models for scale-up well worth consideration.

Given that numerous community and university organizations already exist and offer networks, resources and a rich knowledge of their local communities, increasing the capacity of existing groups could be the best path forward. In some cities, the presence of a college or university with interested faculty members could leverage students and institutional resources; in other communities, a group of retired engineers, technicians, or tradespeople could work together to start an assistive technology group. A challenge of such a modular approach could be transferring the capacity, knowledge, and lessons learned from one group to another. One possible solution to help foster a unified capacity building effort would be to establish a national AT volunteer project that would assist groups in setting scale-up targets, organize collaborative conferences for AT groups from coast to coast, and serve as a coordinating ship-head for public relations and advocacy. Another role of this project could be to establish an online communications portal to connect volunteers, researchers and AT users to each other and to the resources they need. Through this portal, groups could share ideas and information about projects, potential volunteers could locate groups in their area, and AT users could locate volunteers. Online collaboration could be supplemented by physical meetings or forums in each community in which AT users, volunteers, researchers, and relevant community organizations establish links and discuss AT issues, needs, and gaps.

A central part of scaling up the role of the voluntary and education sectors is the need for volunteers who will be involved in building the capacity of the organizations that serve each community. These may include volunteers who do not have the interest or technical skills required for designing and building assistive devices. They may be involved in conducting outreach to inform AT users, their parents and caregivers, or relevant community organizations about the availability of such services, coordinating volunteer schedules, recruiting new volunteers, and other critical administrative and leadership tasks. The contribution of these individuals, it should be noted, has been an integral part of the growth of EWB Canada.

\section{LIMITATIONS}

While the mobilization of the voluntary and education sectors can have a significant impact on AT economics, realizing this potential comes with challenges. Moreover, this impact will be felt on a subset of the types of assistive devices, not all assistive technology.

\section{A. Limited Training and Knowledge}

One of the key challenges in harnessing the power of the voluntary and education sectors to design and build assistive technology is the limited specific training and knowledge of volunteers. While designers, engineers, and those working in the skilled trades may have invaluable technical skills in their fields, most incoming volunteers will have limited AT-specific knowledge and experience. Furthermore, engineering students may have little or no practical experience. Therefore, quality training and mentorship will be essential to ensure that skilled volunteers can transfer their abilities into an AT context. However, the sheer breadth of AT means that people of all skill levels can be involved in AT development. While only highly experience computer engineers may be capable of designing extremely specialized computer interfaces, many potential volunteers could be capable of adapting a musical instrument by mounting it on a table so a child in a wheelchair can wheel up to it and play. 


\section{B. Classes of Devices and Regulatory Issues}

A complicating factor for technical volunteers who build assistive devices is the need for regulatory approvals for some classes of devices. These may include medical or safety classifications, which, due to their requirement for inspections and legal expertise, may result in unreasonable costs for a device designed for just one person. In Canada, medical devices-including assistive devices-are classified from Classes I to IV. Class I devices are non-invasive and low-risk, and do not need to be licensed [25]. Licensing is mandatory for devices in Classes II through IV. As emphasized by Figure 1, the voluntary and education sectors would be best suited to developing simple devices with low demand (i.e. small markets) and that do not require medical device or safety approval.

\section{CONCLUSION}

This paper presents a framework for improving the economics of assistive technology for people with disabilities. Specifically, it may be possible to create customized assistive devices for specialized needs by engaging talented engineers, designers, and other people with technical skills. Furthermore, by having these individuals volunteer their time to create customized devices can be affordable for persons with disabilities. The high rates of disability in Canada and the large numbers of technical professionals, students, and technicians indicate that there is a need for such volunteer services and that the human resources exist to meet these needs. The voluntary and education sectors will not solve all problems in AT economics; however, they could solve the problem of the need for relatively simple assistive devices that have exceedingly small market sizes. Through goodwill, technical skills, and scaling up existing efforts, these sectors could positively affect on the quality of life of thousands of people with disabilities.

\section{ACKNOWLEDGMENTS}

The authors thank Lisa Romkey and Jorge Silva for their suggestions that helped to form the ideas of this manuscript. The assistance of the organizations and institutions mentioned in this paper in providing statistics and details about their work was also invaluable.

\section{REFERENCES}

[1] Statistics Canada, Participation and Activity Limitation Survey 2006. Ottawa, ON: Government of Canada, 2006.

[2] D. Wilson-Costello, H. Friedman, N. Minich, A. Fanaroff, and M. Hack, "Improved survival rates with increased neurodevelopmental disability for extremely low birth weight infants in the 1990s," Pediatrics, vol. 115, pp. 997-1003, April 2005.

[3] Government of Canada, Canada's Aging Population. Ottawa, ON: Government of Canada, 2002.

[4] (2000, Dec.). Electronic and Information Technology Standards (Section 508). [Online]. Available: http://www.accessboard.gov/sec508/standards.htm

[5] B. O'Day and P. Corcoran, "Assistive technology: problems and policy alternatives," Archives of Physical Medicine and Rehabilitation, vol. 75, pp. 1165-1169, October 1994.

[6] I. Marini, M. Bhakta, and N. Graf, "A content analysis of common concerns of persons with physical disabilities," Journal of Applied Rehabilitation Counseling, vol. 40, no. 1, 2009, pp. 44-49.
[7] D. Higginbotham, "Assessing augmentative and alternative communication technology," Technology and Disability, vol. 2, pp. 42, 1993.

[8] D. M. Steel and M. A. Gray, "Baby boomers' use and perception of recommended assistive technology: a systematic review," Disability and Rehabilitation-Assistive Technology, vol. 4, pp. 129-36, May 2009.

[9] M. Laplante, G. Hendershot, and A. Moss, "Assistive technology devices and home accessibility features: prevalence, payment, needs, and trends," Advance Data, Centers for Disease Control, no. 217, pp. 1-13, September 1992.

[10] J. Jacko, V. Hanson, "Universal access and inclusion in design," Univ Access Info Soc, vol. 2, pp. 1-2, November 2002.

[11] M. Hall, D. Lasby, G. Gumulka, and C. Tyron, "Caring Canadians, Involved Candians: Highlights from the 2004 Canada Survey of Giving, Volunteering and Participating," Government of Canada, June 2006.

[12] (2009, Apr.) About the Tetra Society. Tetra Society, Vancouver, Canada Available: http://www.tetrasociety.org/about/index.php.

[13] J. Lee, S. Blain, M. Casas, D. Kenny, G. Berall, and T. Chau, "A radial basis classifier for the automatic detection of aspiration in children with dysphagia," Journal of Neuroengineering and Rehabilitation, vol. 3, no. 14, pp. 1-17.

[14] A. Mihailidis, J.N. Boger, T. Craig, and J. Hoey, “The COACH prompting system to assist older adults with dementia through handwashing: An efficacy study," BMC Geriatrics, vol. 8, no. 28, pp. 118.

[15] D.J. Zimmerman, "Prosthetics: high-tech support for wounded warriors," The Year in Veterans Affairs and Military Medicine, 20072008 edition, pp. 74-77.

[16] D. Haski-Leventhal et al, "Students' vocational choices and voluntary action: a 12-nation study," Voluntas, vol. 19, pp. 1-21, 2008.

[17] E.M. Perry. "Engineering students and the library - forging that critical first link." Presented at Canadian Design Engineering Network/Canadian Congress on Engineering Education 2007 Conference. [Online]. Available: http://cden2007.eng.umanitoba.ca/resources/papers/60.pdf.

[18] L.E. Carlson and J.F. Sullivan, "Hands-on engineering: learning by doing in the integrated teaching and learning program," International Journal for Engineering Education, vol. 15, no. 1, 1999, pp. 20-31.

[19] J. Zelek. (2006, Mar.) Home page for the SYDE 361 syllabus. Department of Systems Design Engineering, University of Waterloo, Waterloo, Canada. [Online]. Available: http://stargate.uwaterloo.ca/ jzelek/teaching/syde361/.

[20] (2009, Jan.). Annual Report. Engineers Without Borders Canada, Toronto, Canada. [Online]. Available: http://www.ewb.ca/mainsite/pages/publications/AR_2008_EN.pdf.

[21] P.T. Decker, D.P. Mayer, S. Glazerman. (2004, Jun.). The effect of Teach for America on students: findings from a national evaluation. Mathematica Policy Research, Inc., USA. [Online]. Available: http://www.mathematica-mpr.com/publications/pdfs/teach.pdf

[22] (2008). About Us. CanAssist, Victoria, Canada. Available: http://www.canassist.ca/about-us.

[23] R. Prinz, S. Neville, N.J. Livingston, "Development of a fuzzy-based sitto-stand controller," in Proceedings of the IEEE Canadian Conference on Electrical and Computer Engineering, 2007, pp. 1631 - 1634.

[24] B.C. Till, M. Benning, and N.J. Livingston NJ. "The WISP: Wireless Inertial Sensing Package," in Proceedings of New Interfaces for Musical Expression (NIME), 2007, pp. 403-404.

[25] Canadian Agency for Drugs and Technologies in Health, (2007), "Medical device regulation in Canada: a primer," [Online]. Available: http://www.cadth.ca/index.php/en/hta/reports-publications/healthtechnology-update/health-technology-update-issue5/medical-device. 